\title{
ACTUARIAL VACANCIES
}

\section{Actuarial Vacancy at the University of Toronto, Department of Statistics}

The Department of Statistics invites applications for a tenure-stream appointment in Actuarial Science starting July 1, 1991. Salary and rank will be commensurate with qualifications and experience. The successful candidate will have a strong research program, and will be involved in undergraduate and graduate teaching and graduate supervision. Letters of application with curriculum vitae and three letters of reference should be sent to Professor M.S. Srivastava, Acting Chairman, Department of Statistics, University of Toronto, Toronto, Ontario, Canada, M5S 1A1 by January 15, 1991. In accordance with Canadian immigration requirements, this advertisement is directed, in the first instance, to Canadian citizens and permanent residents.

\section{$*^{*} *$ \\ Position in Actuarial Science at the University of Waterloo}

Applications are being accepted for a position in Actuarial Science at the Assistant, Associate or Full Professor level, beginning July, 1991 or later. Applicants must have a $\mathrm{Ph}$. D. in Actuarial Science or closely related area. Individuals with strong research interest and a proven research record, good teaching and communication skills are encouraged to apply. Professional qualifications and practical experience in actuarial science are important. Duties would include, undergraduate and graduate teaching; independent research program including supervision of $\mathrm{Ph}$. D. students working in statistical and probabilistic aspects of Actuarial Science. Salary commensurate with qualifications and experience.

The closing date for applications is 31 January, 1991. Interested individuals should send application with curriculum vitae, and arrange for three letters of reference to be sent to :

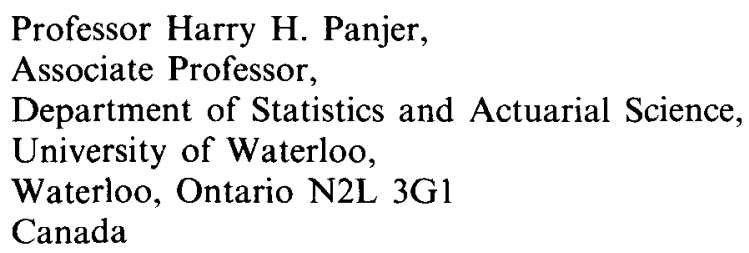


With about 38 faculty and 50 graduate students, the Department of Statistics and Actuarial Science at the University of Waterloo is the largest Department of its kind in Canada. Research activities in the Department cover a broad range of statistics and actuarial science. The Department has a very active Statistical Consulting Service, a close association with the Institute of Insurance and Pension Research which has many industrial contacts, and exceptional computing facilities.

In accordance with Canadian immigration requirements, this advertisement is directed, in the first instance, to Canadian citizens and permanent residents. Qualified women are especially encouraged to apply. An Employment Equity Employer.

\section{$*^{*} *$ \\ Actuarial Vacancy at Concordia University, Department of Mathematics and Statistics}

The Department of Mathematics and Statistics at Concordia University is seeking to fill a tenure-track position at the Assistant Professor level starting 1st August 1991. The department will give priority to candidates in the area of Actuarial Mathematics. Duties will include undergraduate and graduate level teaching, research and participation in the administration and expansion of the actuarial programs.

Interested candidates should send a curriculum vitae and a brief description of field of interest and arrange for three letters of recommendation to be sent prior to December 31, 1990 to :

Dr. W. Byers, Chairman

Department of Mathematics and Statistics

Concordia University

7141 Sherbrooke St. W.

Montreal, Quebec

Canada, H4B 1R6

In accordance with Canadian immigration requirements, this advertisement is directed, in the first instance, to Canadian citizens and permanent residents. 